\title{
Bioefficacy of Geomagnetic Activity in the Period of the COVID-19 Pandemic
}

\author{
S. N. Samsonov ${ }^{a}$ * and S. S. Parshina ${ }^{b}$ \\ a Shafer Institute of Cosmophysical Research and Aeronomy, Siberian Branch, Russian Academy of Sciences-Separate Division \\ of the Federal Research Center Yakut Scientific Center, Siberian Branch, Russian Academy of Sciences, Yakutsk, Russia \\ ${ }^{b}$ Razumovsky State Medical University, Ministry of Health of the Russian Federation, Saratov, Russia \\ *e-mail: s_samsonov@ikfia.ysn.ru \\ Received March 13, 2021; revised April 16, 2021; accepted May 6, 2021
}

\begin{abstract}
The aim of this study is to estimate the peculiarities of the bioefficacy of geomagnetic activity in the period of the COVID-19 pandemic (March-April, 2020) and reveal the specific factors of space weather that impact the sensitivity of the myocardium of healthy volunteers to geomagnetic activity in the given period. The bioefficacy of geomagnetic activity has been studied in healthy volunteers for the first time. There were persons whose initial myocardium disorder was caused by the COVID-19 pandemic. The study continued for 2 months (March-April, 2020) with the daily control of the T-wave coefficient in the electrocardiogram phase portrait, the daily $K p$ index of the geomagnetic activity, dynamical solar wind pressure, $B z$ components of the interplanetary magnetic field, and solar radiation with the wave length of $10.7 \mathrm{~cm}$. Two types of responses of the cardiovascular system were revealed-immediate (typical for cardio-sensitive volunteers) and delayed (for cardio-insensitive persons). The analysis of the extended spectrum of the space-weather parameters made it possible for the first time to determine the combination and the value of geophysical features of geomagnetic activity that cause delayed response (for 1-2 days) in cardio-insensitive persons: the daily $K p$ index over 20 relative units, the dynamical solar wind pressure over $2.0 \mathrm{nPa}$, and the negative value of $B z$ components of the interplanetary magnetic field.
\end{abstract}

Keywords: geomagnetic activity, solar wind, interplanetary magnetic field, cardiovascular system, COVID-19

DOI: $10.1134 / \mathrm{S} 0001433821080065$

\section{INTRODUCTION}

It is known that cardiovascular and nervous systems are the most important systems of the human body that respond to the effects of space-weather factors (Chizhevskii, 1976; Halberg et al., 2000; Cornelissen et al., 2002, 2008; Gurfinkel, 2004; Martynyuk, 2007; Breus et al., 2008; Martynyuk et al., 2008; Samsonov et al., 2008; Ozheredov et al., 2009; Ozheredov and Breus, 2017; Otradnova et al., 2019; Shumilov et al., 2020).

That is why researchers are interested in studying the influence of geomagnetic disturbances on the state of the myocardium of healthy volunteers under various external physical conditions (different latitudes of residence, different meteorological parameters, etc.) (Kleimenova et al., 2007; Parshina et al., 2020a).

A number of authors believe that the degree of influence of geomagnetic activity depends on the Earth's weather (Gurfinkel et al., 2018). For example, it was found that the biotropy of magnetic storms in winter is much higher than in summer (Kleimenova et al., 2007).
It is known that space weather, particularly its parameters such as the velocity and density of particles and the dynamic pressure of the solar wind, as well as the interplanetary magnetic field (IMF) components and the electromagnetic radiation of the Sun in various frequency ranges (from radio to X-ray radiation), exert a certain effect on the state of the body (Samsonov, 2010). The biotropy of stable quasi-sinusoidal $P c 1$ geomagnetic pulsations at middle and low latitudes and irregular geomagnetic pulsations $P i 1$ with periods of $0.5-3 \mathrm{~Hz}$ at subauroral latitudes was also shown (Kleimenova et al., 2007; Samsonov et al., 2013).

Various mechanisms of the described phenomena are discussed (Lednev, 2003; Bingi, 2016; Vladimirskii, 2016); however, there is no final clarity on this issue yet. For example, it is known that the state of the myocardium of both healthy and sick people is largely determined by social conditions. In addition, the psychological state of the surveyed subjects is of significant importance. It was shown that geomagnetic disturbances have different effects on individuals with and without heightened anxiety. Groups of volunteers psychologically sensitive and psychologically insensi- 
tive to geomagnetic disturbances were described (Kodochigova et al., 2018).

In 2020, during the COVID-19 pandemic, both healthy and sick people had unique psychological and social stress conditions of life that have had no analogues over the past decades: the drastic increase in the incidence of coronavirus infection, numerous lethal outcomes, the insolvency of healthcare systems in such a global epidemic, a shortage of drugs in the pharmacy network, working remotely, quarantine mode, restrictions on the usual ways of communication with family and friends, closure of enterprises, uncertainty about the future, etc. Most of the modern population of Russia and the world as a whole found themselves in such conditions for the first time. In addition, people experience the influence of external physical factors such as meteorological and spaceweather factors, primarily geomagnetic disturbances.

There are several studies on the state of the cardiovascular system of healthy volunteers during the COVID-19 pandemic. For example, according to Parshina et al. (2020b), during the COVID-19 pandemic, myocardial repolarization processes were disturbed in $83.4 \%$ of healthy volunteer doctors, indicating a decrease in myocardial adaptive reserves and the development of myocardial dysfunction against the background of increased activity of the mechanisms of sympathetic regulation of the heart. The authors of the mentioned study also compared the state of the myocardium of healthy volunteers in 2020 with the results of similar studies performed conducted in 2014 and 2019 (using the same algorithm and the same equipment) and found that the index reflecting the disturbance of myocardial repolarization in 2020 was statistically significantly higher than that in 2014 and 2019.

However, it is known that, during an epidemic (especially the COVID-19 pandemic), the initial state of the myocardium is extremely important, because it determines the risk of developing myocardial damage in the event of coronavirus infection and increases the risk of hospital mortality (Capotosto et al., 2020).

We found no papers on the response of the myocardium of healthy volunteers to geomagnetic disturbances during the COVID-19 pandemic in the available literature. One factor explaining this situation is the need for a multiannual database, which would make it possible to compare the response of healthy volunteers to geomagnetic disturbances during the pandemic with the results of previous stages of observation to identify the specific features of the year of 2020.

We had at our disposal the database of the Geliomed-2 multilatitude biophysical experiment on the study of the influence of space-weather factors on human health in the Arctic (Tiksi settlement), subarctic (Yakutsk), and temperate (Saratov) latitudes (Parshina et al., 2020a). This database includes measurements since 2014, which makes it possible to compare the responses of healthy volunteers to geomagnetic distur- bances in the period before the pandemic with the responses of the surveyed volunteers in 2020, during the COVID-19 pandemic. The observation groups in this experiment were mainly constant for 7 years in terms of the composition of volunteers, the type of equipment, and the type of examination algorithm. The database includes over 28000 measurements only for the group of volunteers in midlatitudes.

The objectives of the study were to assess the bioefficacy of geomagnetic disturbances in the midst of the COVID-19 pandemic (March-April 2020) and identify the specific space weather factors that affect the sensitivity of the myocardium of healthy volunteers to geomagnetic disturbances during this period.

\section{MATERIALS AND METHODS}

Our study continued for 2 months (March-April 2020). The ECG phase portrait and blood pressure were monitored daily according to the established algorithm (Parshina et al., 2020a). The spring season is transitional: at this time, the most pronounced changes in the amount and amplitude of the geomagnetic disturbance of the Earth occur, which makes it possible to more precisely reveal the responses of the cardiovascular system indices.

Geomagnetic activity was estimated by the global geomagnetic disturbance index - the daily value of the $K p$ index-every day during the entire observation period. The $K p$ index (arbitrary units) differs from other space-weather indices by the logarithmic measurement scale and best describes weak geomagnetic disturbances. As was shown by Samsonov (2013), even a weak geomagnetic disturbance affects the state of the human cardiovascular system.

The dynamic pressure of the solar wind was used as a parameter characterizing the influence of the solar wind on the state of the cardiovascular system, and the $B z$ component was used as a parameter characterizing the influence of the interplanetary magnetic field (IMF). The possible influence of the electromagnetic radiation of the Sun was estimated from a solar radio emission with a wavelength of $10.7 \mathrm{~cm}$. This parameter reflects the changes in the temperature and density of the Sun. The indicated daily solar-activity data were retrieved from the NASA website (https://omniweb. gsfc.nasa.gov). The solar wind and interplanetary magnetic field data were obtained from the WIND satellite located at the $\mathrm{L}_{1}$ Lagrange point.

The study of surface meteorological parameters included the assessment of air temperature, relative air humidity, atmospheric pressure, and wind speed. Meteorological data were retrieved from http:// www.pogodaiklimat.ru and http://weatherarchive.ru/ Temperature/Saratov/April-2020.

The electrocardiogram (ECG) in phase space was assessed with a Fazagraf cardiograph (Fainzilberg, 1998, 2008). The T-wave symmetry coefficient (TSC), 
which reflects the ventricular myocardium repolarization, was determined. TSC is a component of the ECG phase portrait that is most sensitive to external influences (including the effects of space-weather factors) on the myocardium (Fainzilberg, 1998; Vishnevskii et al., 2003). This index is an informative criterion of adaptive reserves of the myocardium. It reflects the features of the electrogenesis in the myocardium, the activity of the mechanisms of sympathetic regulation, and the degree of myocardial vascularization. The TSC value makes it possible to diagnose the early signs of electrophysiological changes in the myocardium. For example, the TSC value $\geq 0.72$ is a marker of myocardial dysfunction (Chaban et al., 2009; Fainzilberg, 2017).

In this study, we used the TSC data of the phase portrait of ECG at rest. Normally, the TSC value is $0.45-0.70$ arb. units. An increase in the TSC value is correlated with an increase in disturbances in myocardial repolarization and the risk of ischemic changes. The cardiograph has its software for a PC, which makes it possible to distinguish the states "norm" (TSC 0.45-0.70), "fatigue" (TSC 0.71-0.99), and "overload" (TSC $\geq 1.00$ ) of the myocardium by the state of myocardial repolarization processes (Ustroistvo..., 2010).

The observation group initially included 21 healthy volunteers; however, 2 weeks after the beginning of the study, due to the development of the COVID-19 epidemic and the transition to remote work, the number of subjects who participated in the monitoring until the end of April 2020 was reduced to 11 . All 11 participants in the monitoring study were doctors working at the RZhD-Meditsina Clinical Hospital in Saratov, on the basis of which the next stage of the Geliomed-2 study was carried out. Only this circumstance made it possible to perform this stage of monitoring. After the end of monitoring, five subjects were excluded from the observation group, because there were numerous gaps in their data, which made it impossible to analyze the TSC dynamics depending on the changes in geomagnetic disturbance. Thus, the observation group ultimately consisted of six subjects. A total of 246 TSC measurements were analyzed. All subjects were women whose average age was $38.0 \pm 6.4$ years.

The data-analysis algorithm included the construction of plots of changes in geomagnetic disturbance according to the daily $K p$ index, dynamic pressure of the solar wind, $B z$ component of the IMF, and radio emission from the Sun with a wavelength of $10.7 \mathrm{~cm}$ for the entire observation period; the construction of individual plots of dynamic changes in TSC for each of the participants throughout the observation period for further identification of cardio-sensitive and cardio-insensitive volunteers (individual cardiac sensitivity); the assessment of group cardiac sensitivity to space weather parameters; and determi- nation of the average TSC value for each volunteer and for the group.

The individual cardiac sensitivity of the volunteers to geomagnetic disturbances was determined by the synchronization of the $K p$-TSC indices in the course of the 2-month observation. In the case of $K p$-TSC synchronization (coincidence of the maxima of these indices in the analysis of their time series during the 60 -day monitoring period) in more than $66.7 \%$ of the $K p$ index peaks, the subject was considered cardiosensitive to geomagnetic disturbances. The group cardiac sensitivity (or the group effect of cardiac sensitivity) was determined as the percentage of the cardiosensitive volunteers to the total number of volunteers in the observation group (Parshina et al., 2020a).

Thus, the terms cardiac sensitivity and cardiac insensitivity used by us reflect the objectively recorded response of the myocardium to fluctuations in geomagnetic disturbance. We recorded no subjective sensations in the area of the heart (discomfort, pain, etc.) in healthy volunteers during geomagnetic disturbances.

Mathematical processing of the data was performed by an original method using a specially developed interactive software package in the Python programming language intended for the analysis and visualization of the results of a study of the synchronization of the parameters of repolarization of the ventricular myocardium with the parameters of space weather, which allows the classification of volunteers (Molchanov et al., 2019; Petrova et al., 2021). The results were plotted and statistical calculations were performed using the Origin and Medstat software. Intergroup comparisons were performed using the $\chi^{2}$ test and Fisher's exact test.

\section{RESULTS}

During the study period (March-April 2020), the geomagnetic disturbance was characterized by the emergence of four maxima of the daily $K p$ index with an amplitude of more than 20 arb. units (Fig. 1). The maxima of the daily $K p$ index were detected on the 14th, 20th, 26th, and 34th days of monitoring; the $K p$ amplitude was $20,22,21$, and 21 arb. units, respectively.

The mean TSC value in the group of volunteers was $0.840 \pm 0.007$ arb. units, which exceeded the normal TSC amplitude (below 0.70 arb. units) and indicated the initial disturbance of the myocardial repolarization processes to the "myocardial fatigue" grade.

Of all the volunteers examined, only volunteer B5 showed cardiac sensitivity to geomagnetic disturbances: the $K p-\mathrm{TSC}$ synchronization was observed in $75 \%$ of the maxima of the daily $K p$ index (the first, second, and fourth maxima). The myocardial response to the third $K p$ maximum was not observed. Fluctuations in TSC in volunteer B5 during the monitoring period ranged from 0.6 to 1.5 arb. units; the 


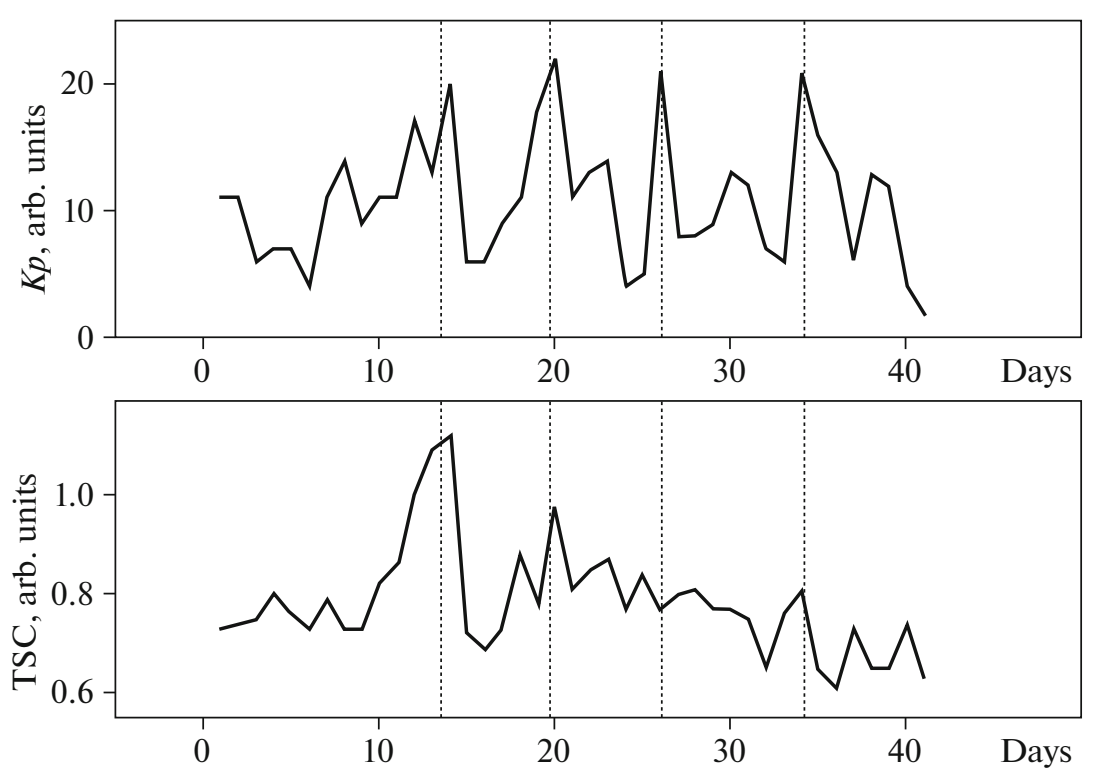

Fig. 1. Variations in the TSC of the cardio-sensitive volunteer B5 upon changes in geomagnetic disturbance. Here and below, in Figs. 2-4, the abscissa axis shows the days of monitoring (March-April 2020).

mean TSC value was $0.78 \pm 0.12$ arb. units, which corresponded to the disturbance of the myocardial repolarization processes and the "myocardial fatigue" grade.

It should be noted that the amplitude of all four maxima of geophysical disturbances for the entire observation period was nearly the same $(20,22,21$, and 21 arb. units) and the response of the myocardium to them was completely different in amplitude (see Fig. 1). For example, the first maximum of geophysical activity with an amplitude $K p=20$ arb. units caused a TSC response with an amplitude of $1.12 \mathrm{arb}$. units; the second maximum ( $K p$ amplitude 22 arb. units) caused a TSC response with an amplitude of 0.98 arb. units; the third maximum ( $K p$ amplitude 21 arb. units) caused no response; and the fourth maximum ( $K p$ amplitude 21 arb. units) caused a TSC response with an amplitude of 0.81 arb. units.

The remaining five volunteers (B1, B2, B3, B4, and B6) did not show cardiac sensitivity to geomagnetic disturbances in the period March-April 2020. The response of the myocardium, according to TSC data, was observed in some subjects only in $25-50 \%$ of the maxima of the daily $K p$ index; in the remainder, no $K p$-TSC synchronization was detected throughout the observation period.

The averaged plot of changes in the TSC of the cardio-insensitive volunteers during the monitoring period in 2020 is shown in Fig. 2. It can be seen that none of the maxima of the $K p$ index was accompanied by the occurrence of a maximum of the TSC in response. Thus, the group cardiac sensitivity in the surveyed group of volunteers in 2020 was $16.6 \%$. The analysis of the cardiac sensitivity of volunteers in the
Geliomed project for previous years showed that the group cardiac sensitivity was $38.6-42 \%$ (Parshina et al., 2020).

The analysis of the mean TSC values for each of the cardio-insensitive volunteers showed that their myocardial state was completely different. Myocardial repolarization processes were in the range of normal values (TSC $=0.45-0.70$ arb. units) in only one subject; the mean TSC was $0.69 \pm 0.08$ arb. units (volunteer B2).

The state of the myocardium of two other cardioinsensitive volunteers (B3 and B6) was characterized as "myocardial fatigue:" their mean TSC value was $0.85 \pm 0.15$ and $0.79 \pm 0.08$ arb. units, respectively.

In the cardio-insensitive volunteers B1 and B4, the mean TSC over the observation period was $0.900 \pm$ 0.004 and $0.980 \pm 0.009$ arb. units, respectively; however, significant fluctuations in the TSC during the monitoring period were observed in them (from $0.72 \mathrm{arb}$. units ("myocardial fatigue") to $1.47 \mathrm{arb}$. units ("myocardial overload"), which corresponds to the state of "myocardial fatigue with elements of overload."

Thus, cardiac insensitivity to geomagnetic disturbances was demonstrated by volunteers with both normal and disturbed repolarization of the ventricular myocardium.

A more thorough analysis of the response of the cardio-insensitive volunteers showed that, in this group, the presence of a TSC response to geomagnetic disturbances cannot be ruled out; however, this response differs from that of the cardio-sensitive volunteers. As can be seen in Fig. 2, the first two maxima of the $K p$ index were not accompanied by a TSC response. However, in response to the third and 

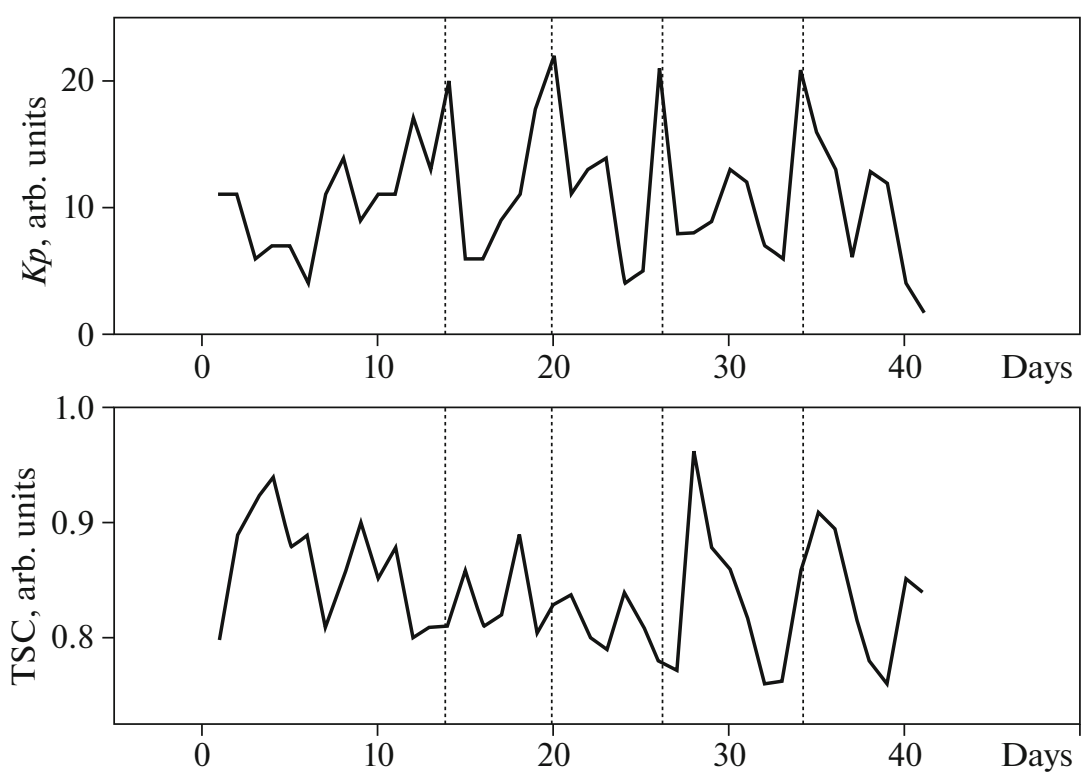

Fig. 2. Variations in the averaged TSC value of the group of cardio-insensitive volunteers upon changes in geomagnetic disturbance.

fourth maxima, TSC maxima emerged with a delay of 1-2 days. For example, the emergence of a TSC maximum in the volunteers was detected 2 days after the third maximum of $K p$ index and 1 day after the fourth maximum.

Thus, a delayed (lagging) response of the cardiovascular system to geomagnetic disturbances in the cardio-insensitive volunteers cannot be ruled out. In this regard, a question arises as to why the geomagnetic disturbance maxima of the same amplitude did not lead to the emergence of a response in TSC to the first two $K p$ maxima, and the two subsequent $K p$ maxima were accompanied by TSC maxima with a delay of 2 and 1 days. To understand the results, we will consider in more detail the changes in the heliogeophysical parameters that may affect the state of the human cardiovascular system, in particular, the data of the $K p$ index of geomagnetic disturbance, the dynamic pressure of the solar wind $(F P)$, the $B z$ component of the IMF, and the radio emission from the Sun with a wavelength of $10.7 \mathrm{~cm}$ (F10.7) (Fig. 3).

In the dynamic pressure of the solar wind, maxima were observed that completely coincided in time with all four maxima of the $K p$ index, which indicates the initiation of the $K p$ maxima by the changing dynamic pressure of the solar wind.

As can be seen in Fig. 3, the third and fourth $K p$ maxima (of interest to us), which are accompanied by a delayed TSC response, coincide with the maximum peak values of the dynamic pressure of the solar wind. The largest negative values of the IMF $B z$ component were recorded in these maxima. For example, the third maximum of the $K p$ index corresponded to the $F P$ value of $3.0 \mathrm{nPa}$ and the IMF $B z$ component of $-0.8 \mathrm{nT}$; the fourth maximum of the $K p$ index corresponded to $F P=2.5 \mathrm{nPa}$ and the IMF $B z$ component $=-0.5 \mathrm{nT}$.

The first and second $K p$ maxima, which were not accompanied by a response of TSC, did not differ in the $K p$ amplitude from the third and fourth maxima, but had different amplitudes of $F P$ and $B z$ component of the IMF.

For example, the first maximum of the $K p$ index corresponded to the values $F P=2.0 \mathrm{nPa}$ and the $B z$ component of the IMF $=-0.2 \mathrm{nT}$; the second maximum corresponded to $F P=2.0 \mathrm{nPa}$ and $\mathrm{Bz}$ component of IMF $=-0.1 \mathrm{nT}$.

Thus, a delayed myocardial response (according to TSC data) occurred at geomagnetic disturbances with $K p>20$ arb. units, the dynamic pressure of the solar wind of $2.0 \mathrm{nPa}$, and negative values of the IMF $B z$ component.

If the identified set was somehow disturbed, then the delayed response of the TSC did not occur, which was confirmed by an analysis of a small-amplitude geomagnetic disturbance on the 30th day of monitoring. This disturbance was characterized by the $K p$ amplitude of 13 arb. units, a sufficiently large $F P$ amplitude $(2.3 \mathrm{nPa})$, and a positive value of the IMF $B z$ component $(0.3 \mathrm{nT})$. In this case, on the 30 th day of monitoring (see Fig. 3), no response of the TSC of the volunteers was observed.

The results suggest the possibility of a delayed (by 1-2 days) response of the myocardium to geomagnetic disturbances, accompanied by the highest values of the dynamic pressure of the solar wind and the 

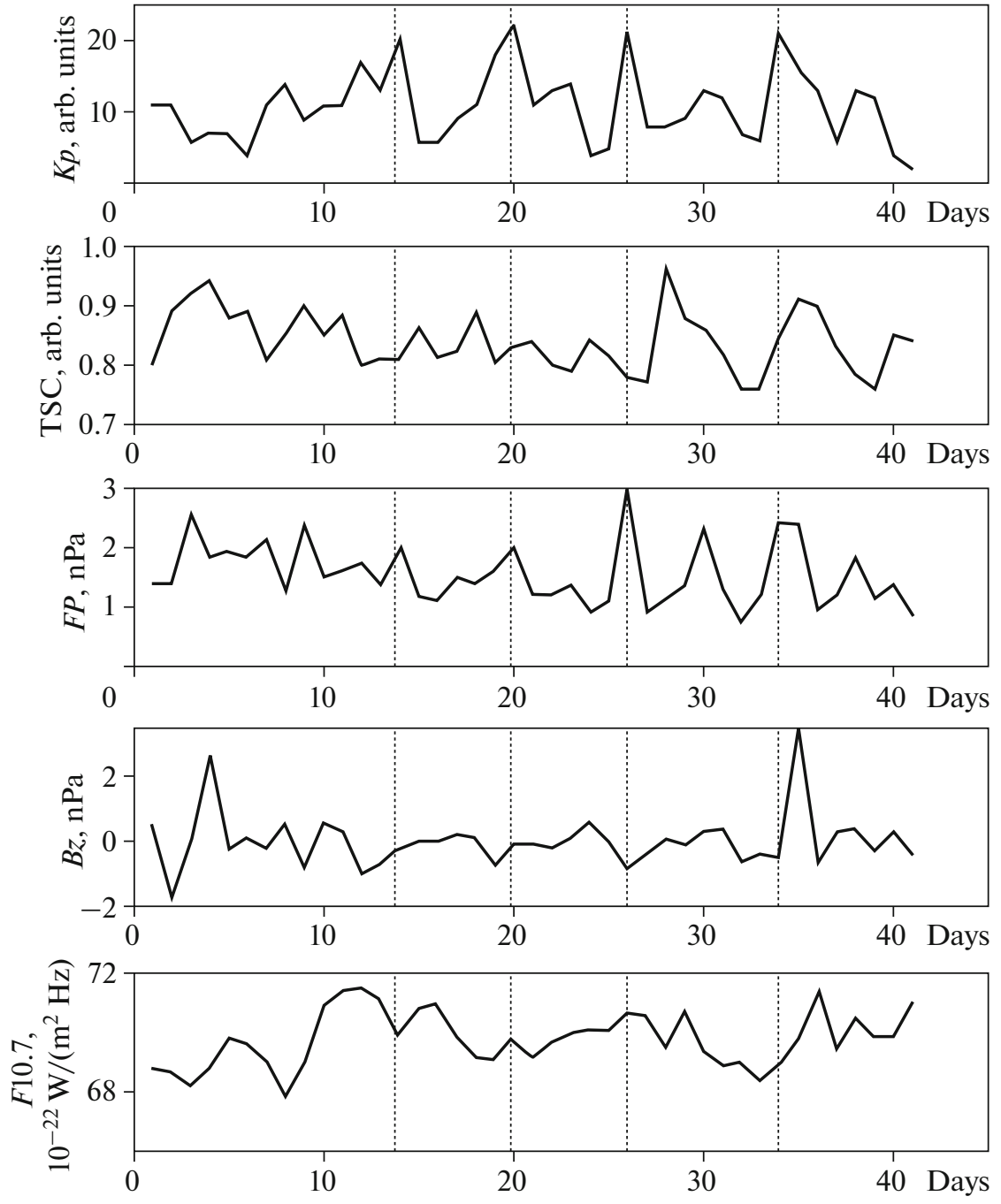

Fig. 3. Variations in the TSC of the group of cardio-insensitive volunteers upon changes in space-weather parameters.

highest in amplitude negative values of the $B z$-component of the IMF even in cardio-insensitive volunteers.

In March-April 2020, positive values of the IMF $\mathrm{Bz}$ component ranging from 0 to $2.2 \mathrm{nT}$ were observed in $57 \%$ of cases and negative values ranging from 0 to $-3.2 \mathrm{nT}$ were observed in $43 \%$.

No correlation was found between the dynamics of solar radio emission with a wavelength of $10.7 \mathrm{~cm}$ and changes in the state of the myocardium according to the TSC data in the cardio-insensitive volunteers during the monitoring period.

However, it cannot be ruled out that the delayed myocardial responses in the cardio-insensitive volunteers were associated with the terrestrial weather rather than with the space weather. With this in mind, we analyzed the changes in some meteorological parameters during the monitoring period, such as the air temperature and humidity, atmospheric pressure, and wind speed (Fig. 4). It was found that the two TSC maxima of interest were not synchronized with the maximum peak values of air temperature, atmospheric pressure, and wind speed. Fluctuations in air humidity only in one case coincided with the peak value of the TSC (the fourth maximum). Thus, there is no evidence that the delayed myocardial responses were caused by the fluctuations in meteorological parameters.

\section{DISCUSSION}

In the study period of March-April 2020, during the height of the COVID-19 pandemic, four weak geomagnetic disturbances were detected which practically did not differ from each other in the $K p$ index values. Only the last two geomagnetic disturbances (the third and fourth ones) were accompanied by slightly higher values of the solar wind dynamic pressure and larger amplitude of the negative value of the $B z$ component of the interplanetary magnetic field. The initial state of the myocardium of healthy volunteers through- 

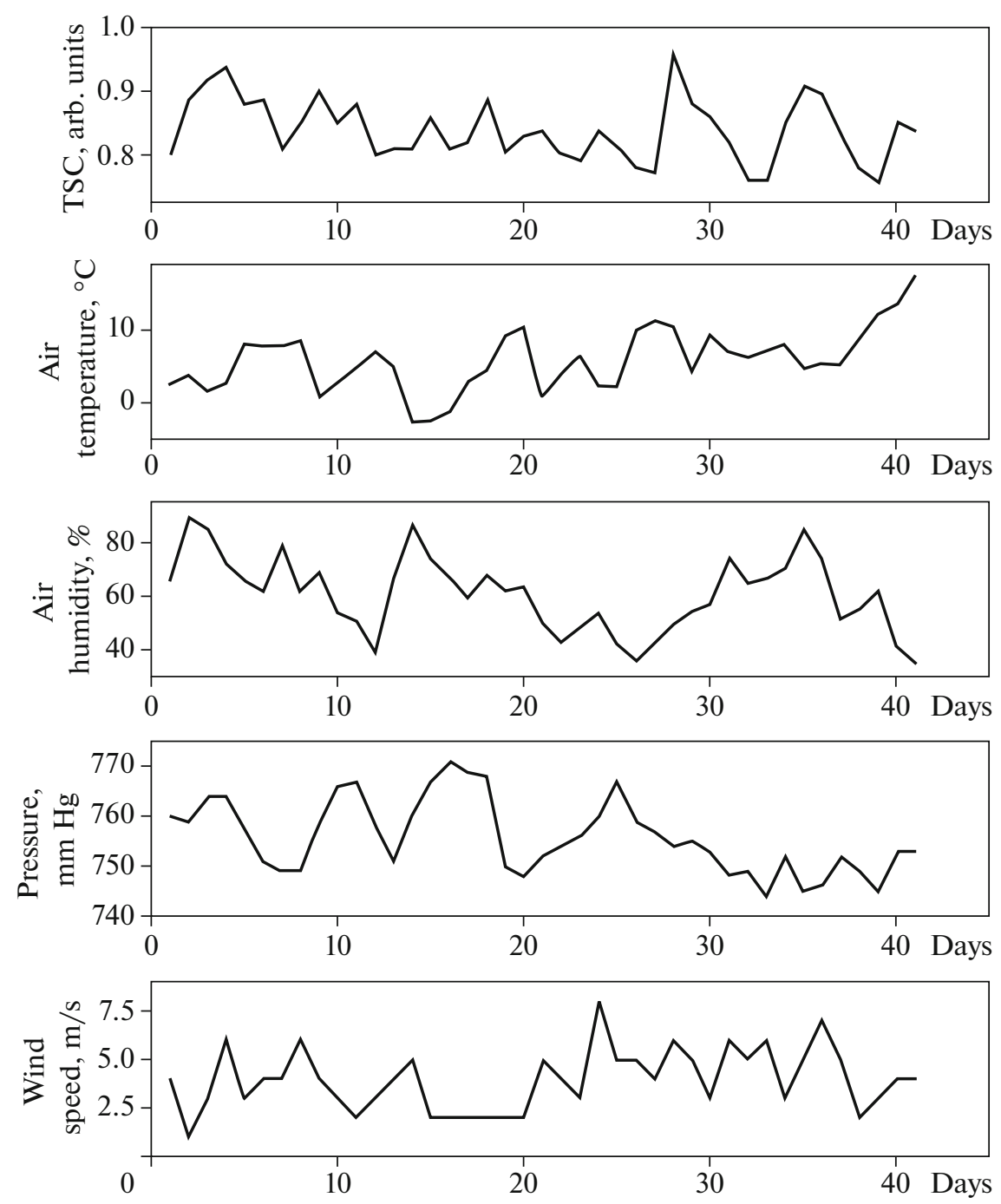

Fig. 4. Variations in the TSC of the group of cardio-insensitive volunteers upon changes in meteorological parameters.

out the monitoring period was characterized by disturbances in repolarization processes, which manifested themselves in an increase in TSC in the electrocardiogram phase portrait to $0.840 \pm 0.007$ arb. units, which exceeds the normal values (less than 0.70 arb. units).

Until now, the effect of space-weather parameters was analyzed only in healthy volunteers without disturbed myocardial repolarization according to TSC data in the electrocardiogram phase portrait. For example, in the studies in 2014 and 2019 in the Geliomed-2 project, normal TSC values $(0.682 \pm 0.006$ and $0.563 \pm$ 0.007 arb. units, respectively) were recorded in healthy volunteers, which is statistically significantly lower than the TSC values in the group of volunteers in the monitoring in 2020 (Parshina et al., 2020b).

Thus, this is the first study to analyze the responses of the cardiovascular system to geomagnetic disturbances in healthy volunteers with disturbed myocardial repolarization processes against the background of the stressful situation caused by the coronavirus pandemic. In the examined group, both cardio-sensitive (16.6\%) and cardio-insensitive ( $83.4 \%$ ) volunteers were identified.

In general, all four geomagnetic disturbances during the study period of the COVID-19 pandemic (March-April 2020) in the volunteers with initially disturbed myocardial repolarization processes were bioeffective: a response to the first, second, and fourth geomagnetic disturbances was observed in the myocardium of the cardio-sensitive volunteers (on the day of the disturbance itself), and the response to the third and fourth disturbances was observed in the myocardium of the cardio-insensitive volunteers (with a delay of $1-2$ days).

Thus, weak geomagnetic disturbances against the background of a calm solar wind caused two different types of myocardial response in volunteers with impaired myocardial repolarization-immediate (on the day of the geomagnetic disturbance) and delayed. 
It is known that immediate responses of the myocardium, characterized by the emergence of peak TSC values on the day of geomagnetic disturbance, arise in response to both weak and more intense geomagnetic disturbances (Samsonov, 2013), which indicates the preservation of physiological synchronization of the cardiovascular system state with the rhythms of the environment (in particular, with the space-weather parameters). This type of myocardial response is characteristic of the healthy volunteers with retained adaptive reserves of the cardiovascular system.

Thus, during the COVID-19 pandemic, some of the volunteers with the initial myocardial disturbances retained the immediate myocardial response on the day of geomagnetic disturbance, which is characteristic of the cardio-sensitive volunteers outside the pandemic period (without a disruption of myocardial repolarization processes).

Among the volunteers that were monitored in 2020 , the cardio-sensitive ones accounted for $16.6 \%$, whereas in previous years (e.g., in 2014) the cardiac sensitivity of healthy volunteers, according to the results of the Geliomed-2 multilatitude monitoring study, was 38.6-42.0\% (Parshina et al., 2020).

The previous periods probably had more significant geomagnetic disturbances, and the results are associated exactly with the differences in the characteristics of the space-weather parameters. However, the group effect of the cardiac sensitivity of healthy volunteers in midlatitudes in the monitoring of 2014 was $42 \%$, although the period of March-April 2014 was also characterized primarily by weak geomagnetic disturbances ( $K p=14-24$ arb. units).

During the monitoring period in March-April 2014 , seven maxima in the daily values of the $K p$ index were detected. Five of them did not exceed $15 \mathrm{arb}$. units, one maximum had a value of 23 arb. units, and another maximum reached approximately 27 arb. units. In March-April 2020, four maxima with amplitudes of approximately 20 arb. units were observed. Therefore, in March-April 2014, at the maximum of the 11-year solar cycle, the geomagnetic disturbance was similar to that observed in March-April 2020.

The comparison of the state of the interplanetary magnetic field (in particular, its $B z$ component) in March-April 2020 with its state in March-April 2014 showed that, in $2020,50 \%$ of events with positive values of the IMF $B z$ component ranging from 0 to $3.4 \mathrm{nT}$ and $50 \%$ of events with negative values ranging from 0 to $-1.7 \mathrm{nT}$ were observed. In March-April 2020, positive values of the IMF $B z$ component ranging from 0 to $2.2 \mathrm{nT}$ were detected in $57 \%$ of cases, and negative values ranging from 0 to $-3.2 \mathrm{nT}$ were detected in $43 \%$ of cases. Thus, the values of the IMF $B z$ component in March-April 2020 only slightly differed from those in March-April 2014. Weather conditions in March-April 2020 were also similar to those in March-April 2014.
It follows from the above that the monitoring period in 2020 differed mostly in the initial state of the cardiovascular system of volunteers rather than in the geophysical parameters (in particular, the $K p$ index values). The disturbance of the myocardial repolarization processes probably caused the features of cardiac sensitivity to geomagnetic disturbances during the pandemic.

The influence of the psychoemotional state of volunteers during the pandemic also cannot be ruled out. It is known that the adaptive responses of the cardiovascular and nervous systems to changes in geomagnetic activity in healthy volunteers are consistent with each other and do not depend on the region of residence. For example, Parshina et al. (2020a, 2020b) described the coincidence of the group effects of cardiac and psychological sensitivity to geomagnetic disturbances. During pandemics, the psychoemotional state of even healthy individuals changes significantly. This also manifested itself during the study period of the COVID-19 pandemic and turned out to be especially important for healthcare workers. For example, according to the results of 59 studies, the risks of psychological maladjustment were identified in doctors in this period (Kisely et al., 2020). Russian scientists also studied the psychoemotional characteristics of healthcare workers during the COVID-19 pandemic. It was shown that, at this time, a significant portion of healthcare workers experience severe symptoms of professional burnout and depression and have an increased level of anxiety and suicidal tendencies (Petrikov et al., 2020).

The atypical ratio of cardio-sensitive and cardioinsensitive volunteers (16.6 and $83.4 \%$, respectively) in the monitoring of 2020 (whereas outside the pandemic period this ratio was, on average, 42 and 58\%) suggests that social tension affects the cardiac sensitivity of healthy volunteers to geomagnetic disturbance. Further studying this problem will probably provide the opportunity to answer the question of how the psychoemotional state can modify the response of the cardiovascular system to external factors.

Despite the fact that our data on cardiac sensitivity during the coronavirus pandemic can hardly be expanded (since the tension of the situation in spring 2020, hopefully, will not repeat itself), their analysis allows us to assess the contribution of the initial state of the cardiovascular system and the initial psychoemotional state to the formation of cardiac sensitivity to space-weather factors. It cannot be ruled out that the key role in changing cardiac sensitivity is played by the appearance of stress-induced myocardial dysfunction rather than by the psychoemotional state. To answer this question, it is necessary to have appropriate reference groups in other time periods. In our case, this is provided by the long-term database of the Geliomed and Geliomed-2 monitoring projects.

In this study, for the first time, we showed the delayed (by 1-2 days) myocardial response to geo-

Vol. $57 \quad$ No. $8 \quad 2021$ 
magnetic disturbances in volunteers in midlatitudes. Previously, the phenomenon of "lagging" was detected only in the cardio-sensitive volunteers in high latitudes (Parshina et al., 2020).

We have found that delayed myocardial responses occur in cardio-insensitive volunteers, i.e., in individuals without immediate myocardial response according to TSC data on the day of geomagnetic disturbance. In the period from March to April 2020 of the COVID-19 pandemic, according to the results of our study, the proportion of such volunteers was $83.4 \%$. The delayed myocardial response was detected in them; the weak geomagnetic disturbances causing this response were distinguished by the highest values of the solar-wind dynamic pressure and increased amplitude of the negative value of the IMF $B z$ component.

It is known that an increase in solar-wind intensity may correlate with an increase in heart rate in healthy volunteers outside the period of a pandemic (Alabdulgader et al., 2018). Our data indicate that, during the COVID-19 pandemic, with an initial disruption of the myocardial repolarization processes, the solar wind (even calm), upon a certain combination with other space-weather parameters, may contribute to responses of the cardiovascular system of a special (delayed) type to geomagnetic disturbance.

The results of this study allow us to discuss the following features of cardiac sensitivity during the COVID-19 pandemic: against the background of an initial disturbance of myocardial repolarization with elements of myocardial dysfunction, healthy cardioinsensitive volunteers develop a delayed (1-2 days) response of the cardiovascular system to weak geomagnetic disturbance. Probably, in the set of characteristics of geomagnetic disturbances that cause a delayed myocardial response, the negative value of the IMF $B z$ component has the greatest influence, because weak geomagnetic disturbances with similar values of the solar-wind dynamic pressure and a positive value of the IMF $B z$ component did not cause such delayed responses in this monitoring study.

The existence of delayed myocardial responses to geomagnetic disturbances in healthy volunteers with an initially disturbed myocardial repolarization makes it possible to better explain the previously obtained data on "delayed" hypertensive crises and acute myocardial infarction 1-2 days after geomagnetic disturbance (Biotropnoe..., 2010).

In addition, the results of this study indicate different types of responses to weak geomagnetic disturbances in volunteers with an initially disturbed myocardial repolarization. The type of response is determined by the specific influencing factor. In particular, the response to space-weather factors of the myocardium with initially disturbed repolarization processes under weak geomagnetic disturbances is largely determined by the negative value of the $B z$ component of the interplanetary magnetic field and the solar wind dynamic pressure.

The results of our study confirm that external physical factors can affect people in different ways depending on their meteosensitivity, health status, and the body's ability to self-regulate (Alabdulgader et al., 2018).

\section{CONCLUSIONS}

This is the first study to analyze the response of the cardiovascular system of healthy volunteers with initially disturbed myocardial repolarization caused by the stressful situation of the coronavirus pandemic to geomagnetic disturbances.

In general, all geomagnetic disturbances during the study period were bioeffective; however, this bioefficacy occurred in cardio-sensitive and cardio-insensitive patients in different ways.

In cardio-sensitive subjects $(16.6 \%)$, the bioefficacy of geomagnetic disturbances occurred by the immediate response of the myocardium on the day of the geomagnetic disturbance. In cardio-insensitive volunteers $(83.4 \%)$, it was found for the first time that geomagnetic disturbances caused a delayed (by $1-2$ days) myocardial response under the condition of a combination of the following values of space-weather parameters: $K p$ more than 20 arb. units, dynamic pressure of the solar wind of more than $2.0 \mathrm{nPa}$, and negative values of the $B z$ component of the interplanetary magnetic field.

The results of this study indicate that healthy volunteers with an initial disruption of myocardial repolarization processes are characterized by different types of sensitivity to weak geomagnetic disturbances, both immediate and delayed. The delayed myocardial responses occur only at a certain set of characteristics of geomagnetic disturbance, dynamic pressure of the solar wind, and $B z$ component of the interplanetary magnetic field.

\section{CONFLICT OF INTEREST}

The authors declare that they have no conflicts of interest.

\section{REFERENCES}

Alabdulgader, A., McCraty, R., Atkinson, M., Dobyns, Y., Vainoras, A., Ragulskis, M., and Stolc, V., Long-term study of heart rate variability responses to changes in the solar and geomagnetic environment, Sci. Rep., 2018, vol. 8, no. 1, id 2663.

Binhi, V.N., A Primary physical mechanism of the biological effects of weak magnetic fields, Biophysics, 2016, vol. 61, no. 1, pp. 170-176.

Biotropnoe vozdeistvie kosmicheskoi pogody: Po materialam rossiisko-ukrainskogo monitoringa "Geliomed" 20032010 (Biotropic Effect of Space Weather: Proceedings of the Russia-Ukraine "Geliomed" Monitoring for 
2003-2010) Ragul'skaya, M.V., Ed., St. Petersburg, VVM, 2010.

Breus, T.K., Ozheredov, V.A., Syuitkina, E.V., and Rogoza, A.N., Some aspects of the biological effects of space weather, J. Atmos. Sol.-Terr. Phys., 2008, vol. 70, pp. 436-441.

Capotosto, L., Nguyen, B.L., Ciardi, M.R., Mastroianni, C., and Vitarelli, A., Heart, COVID-19 and echocardiography, Echocardiography, 2020, vol. 37, no. 9, pp. 14541464.

Chaban, T.I., Chaikovskii, I.A., Fainzil'berg, L.S., Likhogra, I.P., Likhogra, S.P, and Kukharev, O.V., Possibilities of electrocardiogram analysis in the phase space and heart rate variability in patients with hypertension, Ukr. Med. Chasopis, 2009, vol. 70, no. 2, pp. 126-128.

Chizhevsky, A.L., Zemnoe ekho solnechnykh bur' (The Terrestrial Echo of Solar Storms), Moscow: Mysl', 1976.

Cornélissen, G., Halberg, F., Breus, T., Syutkina, E.V., Baevsky, R., and Weydahl, A., Nonphotic solar associations of heart rate variability and myocardial infarction, J. Atmos. Sol.-Terr. Phys., 2002, vol. 64, pp. 707720.

Cornélissen, G., Halberg, F., and Singh, R.B., Unseen space weather also relates to cardiac events, World Heart J., 2008 , vol. 1 , no. 1 , pp. 15-21.

Fainzil'berg, L.S., Information technology for diagnosing the operator's functional state, Upr. Sist. Mash., 1998, no. 4, pp. 40-45.

Fainzil'berg, L.S., Informatsionnye tekhnologii obrabotki signalov slozhnoi formy: Teoriya i praktika (Information Technologies for Complex Signal Progressing: Theory and Practice), Kiev: Nauk. dumka, 2008.

Fainzil'berg, L.S., Osnovy fazagrafii (Basics of Phasography), Kiev, 2017. Gurfinkel', Yu.I., Ishemicheskaya bolezn' serdtsa i solnechnaya aktivnost' (Ischemic Heart Disease and Solar Activity), Moscow: El'f-3, 2004. Gurfinkel', Yu.I., Ozheredov, V.A., Breus, T.K., and Sasonko, M.L., The effects of space and terrestrial weather factors on arterial stiffness and endothelial function in humans, Biophysics, 2018, no. 63, no. 2, pp. 299-306.

Halberg, F., et al. (International BIOCOS Collab.), Crossspectrally coherent $\sim 10.5$ - and 21-year biological and physical cycles, magnetic storms and myocardial infarctions, Neuroendocrinol. Lett., 2000, vol. 21, pp. 233-258.

Kisely, S., Warren, N., McMahon, L., Dalais, S., Henry, I., and Siskind, D., Occurrence, prevention, and management of the psychological effects of emerging virus outbreaks on healthcare workers: rapid review and metaanalysis, Biomed. J., 2020, vol. 369, id m1642. https://www.bmj.com/content/369/bmj.m1642. Accessed May 15, 2020.

Kleimenova, N.G., Kozyreva, O.V., Breus, T.K., and Rapoport, S.I., Seasonal variations in myocardial infarctions and the possible biotropic influence of shortperiod geomagnetic pulsations on the human cardiovascular system, Biophysics, 2007, vol. 52, no. 6, pp. 625-631.

Kodochigova, A.I., Parshina, S.S., Samsonov, S.N., Olenko, E.S., Afanas'eva, T.N., Dzheiranova, M.O., Soltaeva, M.A., Kantaeva, Kh.R., Belousova, K.O., and Petrova, V.D., Influence of heliogeophysical indigna- tion on the psychoemotional state of healthy persons living in middle latitudes, Psikhosom. Integr. Issled., 2018 , vol. 4 , no. $1,0104$.

Lednev, V.V., Biological effects of extremely weak variable magnetic fields: Identification of primary targets, in Modelirovanie geofizicheskikh protsessov (Modeling of Geophysical Processes), Moscow: IFZ RAN, 2003, pp. 130-136.

Martynyuk, V.S., Correlation of the dynamics of electric characteristics of the human organism with space weather variations, Geofiz. Protsessy Biosfera, 2005, vol. 4, nos. 1-2, pp. 53-61.

Martynyuk, V.S., Temur'yants, N.A., and Vladimirskii, B.M., $U$ prirody net plokhoi pogody: Kosmicheskaya pogoda $v$ nashei zhizni (There is No Bad Weather in the Nature: Space Weather in Our Life), Kiev, 2008.

Molchanov, V.A., Podkidyshev, I.A., and Smirnov, E.D., Interactive software for the analysis and visualization of data on the synchronization of parameters of repolarization of ventricular myocardium (according to data of ECG T-wave symmetry ratio) with space weather parameters, in Informatsionnye tekhnologii i matematicheskoe modelirovanie (ITMM-2019): Materialy XVIII Mezhdunar. konf. imeni A.F. Terpugova, Saratov, 2019 (Information Technologies and mathematical Modeling (ITMM-2019): Proceedings of the XVIII Int. Conf. Named After A. F. Terpugov, Saratov, 2019),Tomsk: NTL, 2019, vol. 1, pp. 278-283.

Otradnova, M.I., Rogacheva, S.M., Zhutov, A.S., and Kozlitin, A.M., Influence of solar activity on human heart rate under stress conditions, Ekol. Chel., 2019, no. 7, pp. 4-10.

Ozheredov, V.A. and Breus, T.K., Application of a new method of spectral analysis for detecting synchronous processes in heliobiology, Izv., Atmos. Ocean. Phys., 2018, vol. 54, no. 7, pp. 711-722.

https://doi.org/10.1134/S0001433818070083

Ozheredov, V.A., Breus, T.K., Gurfinkel, Yu.I., Revich, B.A., and Mitrofanova, T.A., Role of space weather factors in health status of people with cardiovascular pathology, Global Telemed. Health Updates: Knowl. Res., 2009, vol. 2, pp. 388-393.

Ozheredov, V.A., Breus, T.K., and Zelenyi, L.M., Connection between the intellectual excitability of internet users and increases in solar activity, Izv., Atmos. Ocean. Phys., 2020, vol. 56, no. 11, pp. 1346-1358. https://doi.org/10.1134/S0001433820110067

Parshina, S.S., Samsonov, S.N., Afanas'eva, T.N., Petrova, P.G., Strekalovskaya, A.A., Petrova, V.D., Kodochigova, A.I., Komzin, K.V., and Tokaeva, L.K., Features of the response of the cardiovascular system to geomagnetic disturbances at different latitudes, Biophysics, 2020a, vol. 65, no. 6, pp. 987-994. https:// www.elibrary.ru/contents.asp?titleid $=7680$.

Parshina, S.S., Samsonov, S.N., Danilova, I.V., Ramazanova, Z.G., Kutina, M.A., Chelysheva, I.V., Gogol', K.V., Zarmanbetova, O.T., Afanas'eva, T.N., and Petrova, V.D., The state of myocardium of healthy volunteer physicians under COVID-19 pandemic, Psikhosom. Integr. Issled., 2020b, vol. 6, no. 4, 0403.

Pavlov, K.I., Syrtsev, A.V., Mukhin, V.N., Arkhimuk, A.N., Mikheeva, E.A., Nikolaeva, S.V., Andieva, N.M., Kamenskaya, V.G., and Petrenko, M.I., The effect of 
environmental factors on the cognitive functions of cadets at a military institute, Izv., Atmos. Ocean. Phys., 2019, vol. 55, no. 10, pp. 1465-1487. https://doi.org/10.1134/S0001433819100086

Petrikov, S.S., Kholmogorova, A.B., Suroegina, A.Yu., Mikita, O.Yu., Roi, A.P., and Rakhmanina, A.A., Professional burnout and symptoms of emotional troubles and distress in healthcare workers during the COVID-19 epidemic, Konsul't. Psikhol. Psikhoter., 2020, vol. 28, no. 2 , pp. $8-45$. https://doi.org/10.17759/cpp.2020280202

Petrova, P.G., Molchanov, V.A., Samsonov, S.N., Parshina, S.S., Strekalovskaya, A.A., Smirnov, E.D., and Podkidyshev, I.A., Software for the analysis and visualization of data on the synchronization of parameters of repolarization of ventricular myocardium (according to data of ECG T-wave symmetry ratio) with space weather parameters, Certificate of the state registration of computer program no. 2021610105, January 12, 2021, Byull., 2021, no. 1. https://fips.ru/registers-doc-view/fips_ servlet?DB $=$ EVM $\&$ DocNumber $=2021610105 \&$ TypeFile $=$ html.

Samsonov, S.N., Space weather parameters and the state of human cardiovascular system: Group and population effects, in Biotropnoe vozdeistvie kosmicheskoi pogody: Po materialam rossiisko-ukrainskogo monitoringa "Geliomed" 2003-2010 (Biotropic Effect of Space Weather: Proceedings of the Russia-Ukraine "Geliomed" Monitoring for 2003-2010), Moscow, VVM, 2010, pp. 69-90.

Samsonov, S.N., Space weather and a state of cardiovascular system of human being with a weakened adaptation system, Odessa Astron. Publ., 2013, vol. 26, no. 2, pp. 297-299.

Samsonov, S.N., Petrova, P.G., Strekalovskaya, A.A., Manykina, V.I., Tomskii, M.I., and Alekseev, R.Z., Association of solar and geophysical disturbances with cardiovascular diseases, Nauka Obraz., 2008, vol. 50, no. 2, pp. 50-55.

Samsonov, S.N., Kleimenova, N.G., Kozyreva, O.V., and Petrova, P.G., The effect of space weather on human heart diseases in subauroral latitudes, Izv., Atmos. Ocean. Phys., 2014, vol. 50, no. 7, pp. 719-727.

Shumilov, O.I., Kasatkina, E.A., Kleimenova, N.G., Khramov, A.V., and Megorskaya, I.P., Suicides and mortality from cardiovascular diseases due to space-weather factors in high latitudes, Izv., Atmos. Ocean. Phys., 2020, vol. 56, no. 8, pp. 799-810. https://doi.org/10.1134/S000143382008006X

Ustroistvo dlya registratsii i obrabotki EKS s pal'tsevymi elektrodami "Fazagraf": Rukovodstvo pol'zovatelya (ECG Signal Recording and Processing Tool "Fazagraf": User Manual), Kiev, 2010.

Varakin, Yu.Ya., Ionova, V.G., Sazanova, E.A., and Sergeenko, N.P., Effects of heliogeophysical disturbances on fluid properties of blood in humans, Izv., Atmos. Ocean. Phys., 2014, vol. 50, no. 7, pp. 728-735.

Vishnevskii, V.V., Fainzil'berg, L.S., and Ragul'skaya, M.V., Solar activity effect on morphological parameters of healthy human ECG, Biomed. Tekhnol. Radioelektron., 2003, no. 3, pp. 3-11.

Vladimirskii, B.M., Space weather and the biosphere-noosphere-technosphere: Driving mechanisms, Nauka Tekhnol. Razrab., 2016, vol. 95, no. 1, pp. 22-36.

Zenchenko, T.A., Medvedeva, A.A., Khorseva, N.I., and Breus, T.K., Characteristics of individual reactions of the cardiovascular system of healthy people to changes in meteorological factors in a wide temperature range, $I z v$., Atmos. Ocean. Phys., 2013, vol. 49, no. 8, pp. 784-798.

Translated by M. Batrukova 